
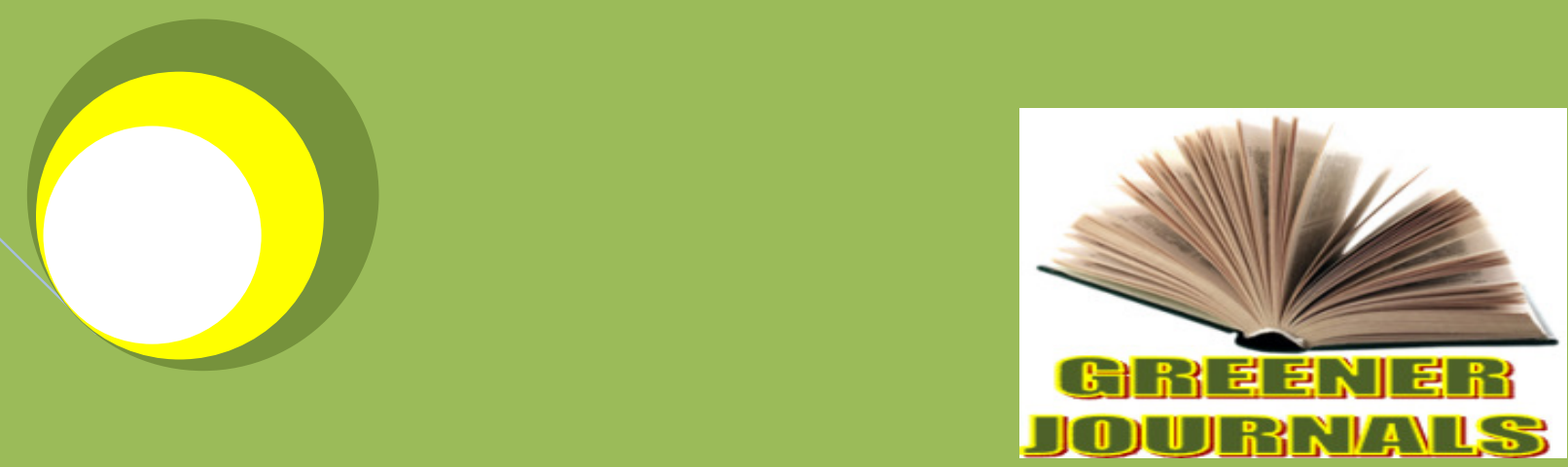

Greener lournal of Elducational Research

\title{
Remediation of \\ Students' Weakness \\ for Enhanced \\ Achievement in \\ Chemistry
}

By

Jegede Samuel A. 


\title{
Remediation of Students' Weakness for Enhanced Achievement in Chemistry
}

\author{
Jegede Samuel A.
}

\author{
Department of Curriculum Studies, Faculty of Education, Ekiti State University, Ado-Ekiti, Nigeria. \\ Corresponding Author's E-mail: canonsamakjeg@yahoo.com
}

\begin{abstract}
The study investigated the effectiveness of Diagnostic Remedial Teaching (DRT) strategy (referred to as Component Task Analysis Model of Instruction, COTAM) in enhancing students' achievement in Chemistry. The sample consisted of 108 SSS 2 students in three instructional groups: DRT, CTM and CG. A test of Achievement in Chemistry (CAT) with an established reliability coefficient of 0.72 was used to ascertain the relative effectiveness of DRT and CTM at 0.05 significant level. It was found that DRT students have a higher mean achievement score than CTM and CG students respectively. This shows that DRT is more effective in curbing the students' weaknesses in regular Chemistry classroom instruction. It is suggested that regular diagnosis and timely remediation of learning difficulties in Chemistry can increase the students' achievement and the acquisition of basic competence and application of chemistry principles.
\end{abstract}

Keywords: Diagnostic Remedial Teaching (DRT), Chemistry students' weaknesses, Conventional Teaching Method.

\section{INTRODUCTION}

Chemistry is a subject of universal interest in human development with regards to the utility of its knowledge in real-life situations likely to be faced by many of the students some day. It has virtually permeated most aspects of our economic and/or public life (Maduabum, 1992). Chemistry embraces a variety of fields of study and is combined with other subjects to satisfy the Senior Secondary School Certificate (SSSC) examination requirements (Jegede, 2003). This could have brought about the essence of Chemistry in the secondary school science curricula. Its lively inter-disciplinary nature seems to reflect an exciting appeal to a wide audience as a focus for examining functional concepts of normal life and systems of health and welfare provisions. As opined by Oyekan (1995), the most exciting prospect of schooling is the harmonious development of individual's potentials coupled with coherent preparation for happy and useful living in the society. On this premise, effective teaching and application of chemical principles in real life situations can improve the quality of human life and preserve the environment.

Chemistry is a core science subject. It is not compulsory for students who are not in the science class but it is compulsory for students in the science class. It is one of the pre-requisite subjects for the study of medicine, pharmacy, biochemistry, engineering and other science and applied science courses in the tertiary institutions. Thus it is vital for the technological development of any nation.

In spite of the importance of chemistry as enumerated above, observation of students' performance in chemistry in the Secondary School Certificate Examination (SSCE) reveal that only a very negligible number of students perform well in the examinations (Jegede, 2003). This frequent poor performance of students in the certificate examination is just pointing to one singular fact that, something is wrong with either the quality of the subject matter (i.e. what the students are taught) or the instructional method (i.e. way they are taught). However, the focus of this study is on the instructional method.

These observed anomalies negate both the aims of the SSSC and the objectives of the chemistry curriculum, which is aimed at satisfying the chemistry requirement of the Senior Secondary School programme in the new National Policy on Education. The said objectives are, to facilitate a transition in the use of scientific concepts and technique acquired in Integrated Science with Chemistry and provides the students with basic knowledge in chemical concepts through efficient selection of content and sequencing. It is also to show chemistry and its link with industry, everyday life, benefits and hazards and its inter-relationship with other subjects and provide a course which is complete for pupils not proceeding to higher education, while it is at the same time a reasonable adequate foundation for a post-secondary course (Federal Ministry of Education, 1985). To some degree, the diagnosis of learning difficulties is regarded by competent teachers as an essential and integral part of regular classroom instruction (Stone and Nielsen, 1982). Diagnostic information will provide a detailed picture of each student's strengths and weaknesses in specific learning areas. The prevalence of students' weaknesses, therefore, demands their incisive diagnosis and instant remediation as teaching progresses in order to arouse interest, improve learning and enhance performance in SSCE Chemistry. 
It becomes imperative for the teacher to grasp the knowledge of the concepts taught and relate them to the child's interest environment and basic needs (Ogwuazor, 1992). However, teacher education programmes should adopt flexible methods of increasing teacher knowledge and pedagogical skills as well as provisions for reflection and correction of students' weakness over a period of time. The possession of a well-defined, integrated subject matter structure (SMS) is expected to translate into a more coherent view of Biology for students and to aid the teacher in the selection of the most appropriate topics to be included in the curriculum (Gess-Newsome \& Lederman, 1993). Accessible and useful SMS imbued with curricular issues can be translated into classroom practices when a teacher has gained experience and mastered professional skills necessary to identify and remedy emerging students' weakness in Chemistry. The teacher is thus the key factor in regular diagnosis, correction and prevention of Chemistry students' weaknesses in order to enhance their academic achievement.

\section{Purpose of the Study}

The main objective of this study is to ascertain the relative effectiveness of Diagnostic Remedial Teaching (DRT) in curbing Chemistry students' weaknesses. Hence, a null hypothesis was generated for the study, that is, there is no significant difference between the performance of students in CTM, DRT and CG when their weaknesses are remedied.

\section{METHODOLOGY}

The sample consisted of 108 (90 male and 90 female) SS 2 students in three comparable secondary schools located in different towns to avoid possible interactions. The students have chosen Chemistry as one of the prospective subject combinations for the SSSC examination. Each of the three schools with its students constitutes the three instructional groups namely; Diagnostic Remedial Teaching (DRT), Conventional Teaching Method (CTM), and Control Group (CG).

The concept of DRT strategy emphasises the principles of careful diagnosis and remediation of students' weaknesses juxtaposed with instructional democracy and learning guidance as springboard to enhance academic achievement and attitude towards Chemistry. It is a form of student-centred approach enriched with exciting instructional aids and continuous assessment as means to promote interest and understanding of chemical concepts. CTM is the traditional form of teaching with little or no consideration for learning guidance, instructional aids, formative evaluation and correction of students' weaknesses as teaching progresses. CG is a group with no instructional treatment but serves as control for the research design.

\section{Instruments}

Two instruments: the Mathematics Prognostic Test (MAPT) and the Chemistry Achievement Test (CAT) were developed and validated as reliable tools for data collection. MAPT is a five-item essay-type test based on the mathematics concepts requisite to the chemistry concepts used for this study. These mathematics concepts were identified to be; variations, simple linear equations, change of subject formula, substitution and logarithm. (Adesoji, 1992; Iroegbu, 1997; Onafowokan, 1998).

The Chemistry Achievement Test (CAT) is a 20 -item, four-option multiple choice objective test measuring students' achievement in some mathematics-related chemistry topics used for this study. They were: gas laws, electrolysis (first and second laws only), mole concept, $\mathrm{pH}$ (calculation) and volumetric analysis.

Content validity of CAT was determined by a panel of five competent Chemistry teachers and educators versed in instructional dispensation and evaluation in Chemistry. They scrutinized the questions item-by-item for correct representation of the selected concepts with the prescribed SSC Chemistry syllabus. Reliability of CAT was established as 0.64 by rationale equivalence method through the application of Kuder-Richardson formula 21.

\section{Research Procedure}

The procedure for this research was in three stages viz the pre-treatment, the treatment and post-treatment stages respectively. The pre-treatment stage involved selecting the schools to be used as the treatment and control groups respectively. Having done this, the researcher visited the schools to discuss the purpose of the study with the principals and through them, got in touch with the SS2 chemistry teachers in each school. He discussed with these teachers on the purpose of the study and arranged with them for the administration of the pre-test. The chemistry teacher in each selected school informed his/her students of the researcher's intention in the there and then, the subjects for the study were chosen as explained in the sample and sampling procedure section. A date was fixed for the pre-test. On the arranged date, the teachers assisted the researcher to administer the pre-test on the selected students in each of the schools. The students' responses were scored and their scores recorded as the pre-test scores. All the questions were retrieved from the subjects after the administration. 
The researcher engaged the services of the SS2 chemistry teachers of the two treatment groups. Detailed lesson plans were developed following the two approaches. Using these in micro-teaching sessions, the two teachers who initially had the same teaching qualification and experience were given training by the researcher on the two approaches respectively. Necessary corrections were made during the respective teaching sessions.

The treatment stage lasted for four (4) weeks with the COTAM treatment group (two (2) weeks for the chemistry instruction) and two (2) weeks for the CMI treatment group. The teaching sessions began the second week for the COTAM treatment group (and with the remediation process) while it began the fourth week for CMI treatment group (and with the instruction on the chemistry concepts). There was no treatment given to the control group.

During the post-treatment stage, the CAT items were rearranged and administered to the students on the fifth day of the second week the treatments were given. CIIAT was also administered as post-test on all three groups. The retention test was administered two weeks after the post-test had been administered. The researcher was present to supervise the administration of each of the tests as well as to monitor the teaching sessions in each of the two schools.

In the DRT class, emphasis was laid on the systematic correction of the students' weaknesses with adequate learning guidance, practical exercises and practice questions. Remediation of students' weaknesses as teaching progresses was expected to enhance their reasoning patterns, cognitive styles, conceptual understandings, academic achievement and pleasant attitudes towards the learning of Biology.

In the CTM group, the subject matter was similar in content as contained in the instructional guide for the DRT students. The CTM group teacher, unlike the DRT teacher, had no marking experience with the West African Examinations council (WAEC) which conduct the SSSC examination. Hence, the teacher was not intimated with the highlighted students' weaknesses and possible examination expectations. The pupils were taught in accordance with the generally accepted practices without any urge for remediation.

The CG students did not receive any instructional treatment and remediation of students' weaknesses while their teacher helped to administer CAT to them. An avenue is thus provided to compare emerging results. At the end of a three-week instructional treatment, CAT was administered for 80 minutes to the three groups as post-test. It was a composite of essay and objective test items that require drawing and expression of ideas in writing.

\section{Data Analysis}

The means and standard deviations of all the CAT scores were computed and used in the comparison of the three groups. It was followed by a simple analysis of variance (ANOVA) to determine whether there is a significant difference between those students exposed to DRT, CTM and CG on CAT at 0.05 level of significance Further analyses were carried out on the post-test scores by using Scheffe method to determine where the group difference lies among the three groups: DRT, CTM and CG. These groups were paired to get the following combinations respectively: DRT and CTM DRT, and CG and CTM and CG. DRT and CG, and CTM and CG. The results were thereafter summarily tabulated and described in tables.

\section{RESULTS}

Analysis of the post-test performances in Tables 1 and 2 indicated that DRT students with a higher mean in achievement score outshined the CTM and CG students on CAT

Table 1: Post-test scores of the groups on CAT

\begin{tabular}{|l|l|l|l|}
\hline \multicolumn{1}{|c|}{ Groups } & \multicolumn{1}{c|}{$\boldsymbol{N}$} & \multicolumn{1}{c|}{ Mean } & S.D \\
\hline DRT & 36 & 16.56 & 1.64 \\
\hline CTM & 36 & 14.50 & 1.85 \\
\hline CG & 36 & 11.83 & 2.36 \\
\hline
\end{tabular}

Table 2: One-way ANOVA for test of significance on Achievement Test

\begin{tabular}{|c|c|c|c|c|c|}
\hline Source & $d f$ & SS & MS & $F$ & $P$ \\
\hline Between Groups & 2 & 403.630 & 201.815 & \multirow{3}{*}{50.1091} & \multirow{3}{*}{$.000^{*}$} \\
\hline Within Groups & 105 & 422.889 & 4.028 & & \\
\hline Total & 107 & 826.519 & & & \\
\hline
\end{tabular}


From the above, $F_{t}$ is less than $F_{c}$. This shows that there were significant differences in the post-test performance of the DRT, CRM and CG students on CAT. It further supports the superiority of DRT over CTM in curbing students' weaknesses in classroom practices.

Table 3: Summary of analysis of comparison group by Scheffe's method

\begin{tabular}{|l|l|l|l|l|}
\hline \multicolumn{1}{|c|}{ Groups } & \multicolumn{1}{|c|}{ Mean } & DRT & CTM & CG \\
\hline DRT & 16.556 & & ${ }^{*}$ & ${ }^{*}$ \\
\hline CTM & 14.500 & & & ${ }^{*}$ \\
\hline CG & 11.833 & & & \\
\hline
\end{tabular}

$\left.{ }^{*}\right)$ denotes pairs of groups significantly different at $p<0.05$

The figures in Table 2 above showed that there were significant differences between (i) DRT and CG on CAT, and (ii) CTM and CG on CAT. The result is expected since the CG students were neither taught with the instructional guide nor their weaknesses remedied.

\section{DISCUSSION}

Effectiveness of DRT strategy for ameliorating the students' weaknesses and preventing learning failure in SSSC Chemistry was upheld by the results of the study (Tables 1 and 2). Such a superior achievement by DRT students over their colleagues exposed to CTM confirmed the essence of learning guidance imbued with good teaching and timely correction of the students' weaknesses in Chemistry.

The findings from this study revealed a significant difference in the achievement mean scores of the experimental and the control groups. Considering the performances of the groups, it was glaring that the COTAM group performed best, followed by the CM group while the Control group had the least performance. This implies that the Component Task Analysis Model of Instruction was superior to the Conventional Model of Instruction as it produced more effective learning than the Conventional method.

This result was not unexpected considering the numerous steps involved in the Component Task Analysis Model of Instruction as compared to the Conventional method. The Component Task Analysis Model of Instruction (COTAM) is a six-step instructional model comprising identification of the Requisite Mathematical Concepts (RMC), prognosis of students' mastery of the RMC, instruction (remedial) on the RMC, evaluation of mastery of the RMC, after remedial instruction on the unit, and unit evaluation. Instruction on the chemistry topic will not hold until students' mastery of the requisite concept is judged satisfactory. This will undoubtedly give the students a good footing in the subject, hence the brighter performance.

The Conventional Model of Instruction on the other hand is a two-step instructional model comprising of instruction on the unit followed by evaluation. This method has been shown not to encourage good performance in students. According to Seweje (2002); in lecture method, peace of lesson is often too fast for the majority of students especially slow writers, who, because they cannot catch up with others find life not easy and thus have very slim chances of passing the class.

This result agrees with findings from previous studies. For instance, it agrees with the findings of Ajeyalemi and Busari (1986) that the use of lecture method as an instructional strategy in Chemistry is one of the factors associated with under-achievement in ' $\mathrm{O}$ ' level chemistry. The finding also supports the recommendation of Katurain Busari (1996) that, since not all students would learn through the use of any specific method, the successful classroom implementation of SSS chemistry curriculum would require enriching the conventional method (lecture method) to promote meaningful learning.

It is to be noted that the two experimental groups achieved significantly.

\section{CONCLUSION}

The findings of this study revealed that the DRT (Component Task Analysis Model of Instruction) produced a better performance and retention in students than the CMT (conventional model of instruction, i.e. the lecture method). The findings also supported Gagne's belief in the learning of a concept or skill. This was confirmed by the better performance and retention the Component Task Analysis Model of Instruction produced in students exposed to it than those exposed to CMT.

The Component Task Analysis Model of Instruction has been found to give room for the teacher to vary his method of teaching to achieve his objectives. It also encourages students to rely on one another as they worked in small groups on the activities more than on the teacher.

These findings have implications for the design of instruction in chemistry. They suggest that chemistry teachers should always probe into students' knowledge of those concepts which serve as foundation to the new 
concept to be taught, especially, the relevant mathematics concepts and take the pain to remedy such requisite concepts before going ahead to teach the desired concept as this will give the students a stronger footing. This is necessary as any structure built or erected on a faulty foundation is bound to collapse. It is only when students have a meaningful understanding of what they are taught and not just rote learning, that they can rightly apply that knowledge to solve real life problems as they come their ways.

This study also reminds teachers of the strength of previous knowledge of mathematics concepts in teaching chemistry. It also shows that remedying students' weakness in mathematical knowledge and skills enhances their performance in chemistry as they now find it easier to learn chemistry, especially those concepts which require certain mathematical knowledge and skills for their understanding. This finding is in support of Ausubel's belief that meaningful learning occurs when there is interaction between the learner's appropriate elements in the knowledge that already exists and the new materials to be learnt. When the students' weaknesses are obviated in progressive Chemistry instruction, learning becomes exciting with ample opportunities for more individuals to study Chemistry and apply chemical knowledge to improve their leaving standards.

\section{REFERENCES}

Ajeyalemi, Duro \& Busari OO (1989). The influence of teacher's cognitive styles on their teaching strategies. Zimbabwe Journal of Educational Research. 1(2): 206-220.

Federal Ministry of Education (1985). Science and technology and CESAC Chemistry curriculum for senior secondary schools in Nigeria. Yaba, Lagos: NERC.

Gess-Newsome J \& Lederman NG (1993). Pre-service Biology teachers' knowledge structures as a function of professional teacher education: A year-long assessment. Science Education. 77(1): 25-45.

Jegede S A (2003). The effect of the component task analysis model of instruction on students' performance in Chemistry. An unpublished Ph.D. thesis, University of Ado-Ekiti, Nigeria.

Maduabum MA. (1992). The role of the biologist in Nigeria's development. Journal of the Science Teachers' Association of Nigeria. 27(2): 18-24.

Ogwuazor KE(1992). Introducing the human angle into the teaching of science and technology in schools. Journal of the Science Teachers' Association of Nigeria. 27(2): 81-83.

Oyekan S O (1995), Social economic and political dimensions of schooling. In B. Ipaye, (Ed). Research on Schooling in Nigeria: An Introductory Reading. Lagos: Chayoobi Printers and Publishers.

Seweje R O (2002). The challenge of science teaching in Nigeria today. Journal of Educational Foundation and Management. 1(1): 208-220.

Stone DR \& Nielsen EC (1982). Educational psychology: The development of teaching skills. New York: Harper \& Row Publishers. 